\title{
UMA QUESTÃO DE HORA E LUGAR: O AMOR QUE NÃO DÁ CERTO EM BEIJO NA BOCA DE CACASO
}

\author{
Débora Racy SOARES (UNICAMP - FAPESP)
}

RESUMO: O objetivo deste artigo é refletir sobre alguns versos de Beijo na boca (1975) de Antônio Carlos de Brito, o Cacaso. Em um primeiro momento, partiremos de algumas de suas canções para entender a concepção de amor que figura neste livro. Depois, pensaremos como o amor e a ironia estão articulados para fundar o desencontro amoroso.

PALAVRAS-CHAVE: Poesia brasileira; Poesia marginal; Cacaso; Beijo na boca.

\begin{abstract}
The purpose of this article is to reflect about some verses of Beijo na boca (1975) by Antônio Carlos de Brito, Cacaso. First, we will approach some of Cacaso's songs, aiming to understand the conception of love that appears in this book. After that, we will think about how love and irony are articulated to establish the "unme(e)t" loving.
\end{abstract}

KEYWORDS: Brazilian poetry; Fringe poetry; Cacaso; Beijo na boca.

\section{Meu coração não é sincero}

Meu lado torto é o direito

Cacaso

Beijo na boca (1975) é o terceiro livro de versos do poeta Antônio Carlos de Brito (1944-1987), mais conhecido por Cacaso no universo literário e cultural da década de setenta.[1] Além de poeta, Cacaso era letrista e costumava se dedicar a ambas as atividades ao mesmo tempo. Já que do "verso nasce a canção", é possível observar certa convergência temática entre os poemas deBeijo na boca e algumas de suas letras, compostas na mesma época da fatura do livro (BRITO, 1982, p.136).

À primeira vista, a lírica amorosa dá tônus ao livro de 1975. No entanto, como procuraremos demonstrar ao longo de nossa reflexão, o "coração" do poeta não é, deveras, "sincero", pois o tema amoroso revelar-se-á uma estratégia poética (e política) diante do contexto de produção de setenta. Já adiantemos: Cacaso é poeta "pérfido" como o definiu seu contemporâneo Francisco Alvim. Nesse sentido, segue as trilhas de poetas modernos importantes como Baudelaire e Fernando Pessoa. Nos poemas 
de Beijo na boca o "fingimento" sempre tem "lugar" e é "sério" (BRITO, 1982, p.87; p.116). Afinal, como enfatiza o poeta, o "sentimento é fingido", mas o "fingimento é verdadeiro" (BRITO, 1997, p.247). Antes, porém, de nos atermos à nossa hipótese, seria interessante refletir se haveria semelhanças entre a concepção de amor que perpassa os versos de Beijo na boca e algumas canções coetâneas.

Tomemos como exemplo "Hora e lugar", composta por Cacaso e musicada por Francis Hime. É sintomático perceber que esta canção anuncia um desencontro fundamental: o amor não dá certo por uma questão de "hora e lugar", entoa o estribilho (BRITO, 1982, p.87). [2] O insucesso amoroso é justificado pelo poeta que "precis(a) de respirar", apesar da "vida" que "vai lá fora" (BRITO, 1982, p.88). Nesse caso, o poeta não concebe o amor como uma solução miraculosa, antídoto ou filtro mágico, capaz de sanar os problemas existenciais da "vida" que "vai lá fora". Pelo contrário, nesta canção, assim como no livro Beijo na boca, o amor é visto de forma nãoidealizada, opondo-se à retórica do amor romântico que perpassa boa parte da literatura ocidental.[3]

O amor, em analogia à "vida" de meados de setenta, soa asfixiante. Não é preciso dizer que, naquela época, havia "certos sinais no ar" que a "literatura captava e poetava" (HOLLANDA, 2000, p.186). Assim, uma parte significativa da produção poética da década de setenta, designada "literatura marginal" pela crítica, pode ser encarada como uma espécie de "texto-testemunho" ou "texto-sintoma" (VIÑAR, 1992, p. 125). Nesse sentido, é interessante pensar, como o faz Seligmann-Silva (2003, p.8), que toda literatura - independente da época de sua produção - guarda um "teor testemunhal" que precisa ser devidamente considerado. Posto de outra forma: se assumirmos que há um "teor testemunhal" inerente tanto aos versos de Beijo na boca quanto às canções de Cacaso, reconheceremos também que ambas as manifestações artísticas podem funcionar como uma espécie de "grafia da memória" ou de "historiografia baseada na memória" (SELIGMANN-SILVA, 2003, p. 389; p. 395). Isso significa que uma leitura que pretenda apreender a riqueza do livro deve privilegiar o olhar diacrônico. Se os modos de ler interferem, diretamente, nos modos de ver, uma leitura que fosse apenas sincrônica tenderia a conceber este livro de 1975 de forma redutora: como mais um livrinho de amor. E já que estamos falando de amor - ou será 
da falta dele? - seria pertinente pensar o movimento de leitura, em sua incompletude melancólica fundamental, como uma reflexão crítica apaixonada. A tarefa do leitor, portanto, seria semelhante àquela dos primeiros românticos alemães de Iena: elevar à máxima potência, como dizia F. Schlegel, os sentidos do texto.

Retomando nossa reflexão sobre a concepção de amor nas canções, reiteramos que, em "Hora e lugar", sobressai o desencontro fundamental, impeditivo quando se trata de conceber qualquer relação, inclusive a amorosa, como porto seguro. Sublinhamos que, como na canção, o desencontro amoroso é o Leitmotiv de Beijo na boca. Logo veremos que a escolha deste tema e suas implicações semânticas refletem na forma como Cacaso arquiteta seus poemas. Adiantamos que o poeta, ao apostar na desestabilização semântica em versos, instaura um movimento de contínuo desmentir que dá o que pensar do ponto de vista analítico. Nosso desafio, portanto, é entender que tal recurso funciona como estratégia linguística e põe em xeque a relação entre o significado e o significante, problematizando qualquer tipo de estabilidade semântica e/ou sentimental. Vê-se, logo pelo título, que o poeta promete algo que não cumpre. Não há beijo na boca, tampouco final feliz, neste livro que mobiliza um verdadeiro tour de force irônico em versos.

Em outra canção, "Pena de paixão", musicada por Nelson Ângelo, o sentimento amoroso é visto como algo negativo, que faz sofrer e causa dor. Assim, o amor "tir(a) toda a ilusão" do poeta, tornando-o "cego e descontente" (BRITO, 1982, p.84). A relação entre a visão e o amor é recorrente em canções de Cacaso. Em "Senhorita", feita em parceria com Novelli, a ausência da amada causa outro efeito: "desilusão de ver" (BRITO, 1982, p.99). Os primeiros versos da letra "Boca de cereja", musicada por Nelson Ângelo, retornam, ligeiramente modificados, no poema "Moda de viola": "os olhos daquela ingrata às vezes/ me castigam às vezes me consolam. / Mas sua boca nunca me beija" (BRITO, 2002, p.91)[4]. Já a "Canção do desamor demais", feita em parceria com João Donato, revela novamente o desencontro. Porém, agora, o descompasso será entre o dizer e a ação: "meu amor diz que me ama / mas jamais me dá um beijo" (BRITO, 1982, p.103). Aliás, esses versos aparecem no início de um poema de Beijo na boca, intitulado "Lá em casa é assim”. Há uma relação intertextual recorrente entre determinadas canções e alguns poemas que precisa ser analisada com 
critério. Como observamos em trabalhos anteriores, se versinhos fecundam canções, o inverso também ocorre.[5]

É interessante pensar, partindo de "Pena de paixão", que em Cacaso o amor desilude - "tir(a) toda a ilusão". Assim, a perda ou, antes, a crítica às ilusões será recorrente em Beijo na boca. EmFedro, Platão compara o amor a uma espécie de doença dos olhos. Ao fazê-lo, sugere que o amor seria não só uma doença da visão, mas também da imaginação, pois criaria ilusões ou uma ymageque não corresponderia à realidade. O amor, concebido como ilusão, será problematizado ao longo do livro de Cacaso, conduzindo a uma crescente suspeição nas imagens e, por fim, a uma crítica ao véu encobridor da fantasia ideológica. Pois a discrepância entre a aparência e a essência, o dito e o sugerido, o explícito e o latente, formatam os versos deste livro de 1975. Note-se, contudo, certa inversão: o poeta torna-se "cego e descontente" devido à desilusão amorosa. Sabe-se que, para a filosofia grega, desde suas origens, "o verbo ver" encontra-se vinculado "ao conhecimento" (BORNHEIM, 1988, p.89). Aqui, entretanto, à maneira de Tirésias - o cego que sabia ver - a cegueira conduz ao conhecimento. Pois é certo que, em Cacaso, "lucidez e dor" ou desilusão amorosa estão intrinsecamente relacionadas (BRITO, 1997, p.246). É como se o poeta precisasse sofrer - e ficar cego - para realmente começar a ver. Nesse sentido, o que parece estar em pauta seria a exigência de uma espécie de reeducação do olhar. Reeducação, aliás, que embasava a "evolução metafísica da visão", associada ao "conceito de orthotes", ao "ver corretamente" (BORNHEIM, 1988, p.89). Abstemo-nos de julgar. O fato é que a poesia - em sua incansável ânsia de re-significação da imago mundi-costuma exigir de seus leitores um outro olhar para as coisas mais familiares. Freud denomina Unheimlich esse outro olhar, mobilizado por aquela inquietante estranheza inerente à poesia. A reboque deste estranhamento do familiar advém o questionamento do mundo pré-fabricado, já dado, conhecido através de imagens congeladas. Assim, quando começamos a olhar para o mundo através dos olhos do poeta, "estamos experimentando não o mistério do conhecimento, mas o mistério do desconhecimento" (PERRONE-MOISÉS, 1988, p.331).

Em Beijo na boca "não há afirmação que se fixe como a derradeira" (ALVIM, 2000, p. 59). A partir dessa estratégia de desdizer, Cacaso inaugura uma poética 
desencontrada em que o mote amoroso funciona como pretexto para reflexões que transcendem o âmbito sentimental. Considerado uma espécie de educação sentimental de sua geração, Beijo na boca, no conjunto da produção poética de Cacaso, chama a atenção justamente por eleger o amor - ou o desamor - como tema[6].

Ao longo do livro, a expectativa do leitor é frustrada diante da promessa de encontro, sinalizada por seu título, pois os versos ensinam que se as "aparências enganam", elas também "revelam” (BRITO, 1997, p.299). O "Happy end" sinaliza o desencontro: "o meu amor e eu / nascemos um para o outro / agora só falta quem nos apresente" (BRITO, 2000, p.13). Através de uma espécie de pedagogia poética, os versos de Beijo na boca ensinam a desconfiar das palavras e das coisas, na forma em que são apresentadas. O título do livro, aliado à capa, funciona como (en)cobertura das intenções dissimuladas do poeta. A capa da primeira edição (1975) faz crer que o livrinho seja repleto de intenções românticas: um pequeno coração, espremido entre duas flores, delimita o alto da página. Nas laterais, mais flores e ramagens. Abaixo do título, "BEIJO NA BÔCA", uma borboleta colore a página, invocando graça e leveza. Na capa da edição de 2000, o novo desenho, de autoria de Cacaso, dos rostos de um casal se beijando, contribui para manter a ilusão sugerida desde a primeira edição.

O poeta "pérfido" exige um leitor hipócrita: logo de antemão, joga com a cumplicidade do leitor, questionando a possibilidade de significados unívocos e estáveis. Assim, através do "poder do não dito de desafiar o dito" - condição semântica da ironia -, os versos de Beijo na boca acumulam sentidos que contrariam o anúncio do título (HUTCHEON, 2000, p.91). Como diz Cacaso (1997, p.183), “a intenção da sinceridade implica sempre uma segunda intenção". Beijo na boca revela o que as aparências escondem: uma poetização de intenções segundas que funciona através domodus operandi da ironia. Veja-se como o título dos poemas contraria a promessa dos versos. Tome-se como exemplo o desencontro anunciado em "Encontro desmarcado": "admiro muito meu amor / porque sempre está por perto de si mesma e / longe de mim e eu tenho / andado muito longe de mim e perto de si mesma" (BRITO, 2000, p.45). Ou ainda "Seresta ao Luar" - "desde que declarei meu amor nunca / mais me olhou de frente", confirmando a "Sina" do poeta: "o amor que não dá certo sempre está por / perto" (BRITO, 2000, p.55; p.19). Nesse sentido, a leitura dos poemas ensina 
que o "leitor distraído" pode bem ser "vítima das aparências enganosas" (BRITO, 1997, p.284). Além disso, o recurso irônico que molda estes versos instala deslocamentos semânticos sucessivos - movimento que pode, no limite, esvaziar qualquer possibilidade de construção de sentidos estáveis.

Em termos analíticos, a dificuldade em lidar com a ironia deve-se ao fato de que este recurso implica "três características semânticas principais": "ele é relacional, inclusivo e diferencial" (HUTCHEON, 2000, p.90). A ironia funciona de forma relacional, pois seus sentidos operam "não apenas entre significados (ditos, não ditos), mas também entre pessoas", isto é, "ironistas, interpretadores, alvos" (HUTCHEON, 2000, p.91). Como a cena da ironia envolve a questão comunicativa, uma coisa é certa: "não há ironia sem ironista" (DUARTE, 2006, p. 19). Daí decorre que não há ironista sem leitor de ironia. Se o ironista é alguém que percebe e explora as ambiguidades da linguagem, em suas múltiplas possibilidades de sentido, o leitor da ironia precisa ser capaz de perceber as intenções do autor. De certa forma, a ironia poética de Cacaso põe o dedo na (má) consciência e não admite qualquer naïveté ou desatenção do leitor.

Do ponto de vista da inclusão, o recurso irônico articula um duplo discurso. $\mathrm{O}$ leitor, intérprete do jogo da ironia, precisa compreender as sutilezas de um movimento que oscila, "muito rapidamente", "entre o dito e o não dito" (HUTCHEON, 2000, p.92). Para surtirem efeito, o dito e o não dito, incluídos na ironia, devem ser lidos simultaneamente. A superposição dos significados gera um acúmulo ou excesso de sentidos, criando um "terceiro composto" irônico, ancorado na diferenciação (HUTCHEON, 2000, p.93). Assim, como diz McCracken, "duas notas tocadas juntas produzem uma terceira nota que é, ao mesmo tempo, ambas e nenhuma delas" (McCRACKEN apud HUTCHEON, 2000, p.93). Veja-se o poema "Contando Vantagem": "muitas mulheres na minha vida. / Eu é que sei o quanto dói” (BRITO, 2000, p.48). Para acharmos graça no poema, precisamos procurar pelo "terceiro composto" irônico que, sem anular a (im)positividade do título e o sentido que emana dos versos, produz a nota diferencial. Nesse caso, é preciso ler a locução contar vantagem, cujo sentido remete à ostentação das conquistas, de forma aritmética. Ou seja, o poeta conta, calcula, faz as contas e pondera que o excesso - "muitas mulheres" 
- causa dor. Retoma-se, portanto, a idéia da lucidez advinda da dor, presente em algumas canções de Cacaso. "Orgulho" opera na mesma chave interpretativa: "decresça e / apareça" (BRITO, 2000, p.50).

Se, em Beijo na boca, o amor não dá certo por uma questão de hora e lugar, os poemas só funcionam por causa deste desencontro fundamental. A complexidade semântica mobilizada pelo recurso irônico - produtivo quando conjugado à temática do desamor - potencializa sentidos pelo negativo. Ao assinalar e ressaltar a diferença do que parece semelhante, o discurso irônico revela sua "natureza transideológica" (HUTCHEON, 2000, p.34). Assim, ao mesmo tempo em que problematiza a linguagem e os referenciais estanques e estáveis, a ironia questiona as formas dominantes de representação do mundo. No início do trabalho mencionamos que o tema amoroso funciona como estratégia poética e política no contexto de produção de Beijo na boca. A escolha da ironia como recurso linguístico, ao instaurar alternâncias do dizer, responde, de certa maneira, a toda demanda reprimida no mundo real.

\section{REFERÊNCIAS}

ALVIM, C. de A. Esses poetas de hoje. In: BRITO, A. C. de. Beijo na boca. Rio de Janeiro: 7Letras, 2000. p. 59-61.

BORNHEIM, G. A. As metamorfoses do olhar. In: NOVAES, A. (Org.). O olhar. São Paulo: Companhia das Letras, 1988. p. 89-93.

BRITO, A. C. de. Beijo na boca. Rio de Janeiro: Vida de Artista, 1975.

Mar de mineiro. Rio de Janeiro: 1982.

Não quero prosa. Org. Vilma Arêas. Campinas/Rio de Janeiro:

UNICAMP/UFRJ, 1997.

Beijo na boca. Rio de Janeiro: 7Letras, 2000.

Lero-lero. Rio de Janeiro/São Paulo: 7Letras/Cosac \& Naify, 2002.

DUARTE, L. P. Ironia e humor na literatura. Belo Horizonte/São Paulo: PUCMinas/Alameda, 2006.

HOLLANDA, H. B. de. Depois do poemão. In: GASPARI, E.; VENTURA, Z.;

HOLLANDA, H. B. de.Cultura em trânsito: da repressão à abertura. Rio de Janeiro: Aeroplano, 2000. p.186-190.

HUTCHEON, L. Teoria e política da ironia. Tradução de Julio Jeha. Belo Horizonte: UFMG, 2000. 
PERRONE-MOISÉS, L. Pensar é estar doente dos olhos. In: NOVAES, A. (Org.). O olhar. São Paulo: Companhia das Letras, 1988. p. 327-346.

ROUGEMONT, D. de. A história do amor no ocidente. Prefácio de Marcelo Coelho. Tradução de Paulo Brandi e Ethel Brandi Cachapuz. São Paulo: Ediouro, 2003.

SELIGMANN-SILVA, M. (Org.). História, memória, literatura: O testemunho na Era das Catástrofes. Campinas: UNICAMP, 2003.

SOARES, D. R. Um frenesi na corda bamba - Análise crítica da obra poética Grupo Escolar(1974) de Antônio Carlos de Brito. 2003. 220 f. Dissertação (Mestrado) Faculdade de Ciências e Letras, UNESP, Araraquara, 2003. O ornitólogo e a arapuca: Notas sobre A palavra cerzida e Grupo escolar de Cacaso.Revista TextoPoético, v. 4, p. 1-9, 2007. www.textopoetico.org VIÑAR, M. e M. Exílio e tortura. Tradução de Wladimir Barreto Lisboa. São Paulo: Escuta, 1992.

[1] Será utilizada, como referência para as citações, a segunda edição do livro Beijo na boca, publicada em 2000, pois as páginas da primeira edição, de 1975, não estão numeradas.

[2] O último livro de Cacaso, Mar de mineiro (1982) é um misto de poemas e canções, onde estas predominam. A maior parte das canções foi produzida na década anterior.

[3] Para um aprofundamento sobre o tema, confira $A$ história do amor no ocidente (2003).

[4] "Moda de Viola" aparece no livro Segunda classe (1975), feito em parceria com Luís Olavo Fontes. Utilizamos como referência Lero-lero (2002), reunião de todas as obras poéticas de Cacaso. Assim como Beijo na boca, Segunda classe foi publicado pela coleção carioca "Vida de artista", organizada por Cacaso. Além desses dois livros, esta coleção também foi responsável pela edição de Aqueles papéis (1975), de Zuca Sardan (Carlos Saldanha), América (1975), de Chacal (Ricardo de Carvalho Duarte), A vida alheia (1975), de Eudoro Augusto, e Na corda bamba(1978), de Cacaso.

[5] Nesse sentido, confira SOARES, 2003 e 2007.

[6] Além de Beijo na boca, a produção poética de Cacaso é constituída pelos seguintes livros: A palavra cerzida (1967), Grupo escolar (1974), Segunda classe (1975), com Luís Olavo Fontes, Na corda bamba (1978) e Mar de mineiro (1982). 